\title{
Psychological barriers
}

\author{
T C Skinner \\ Department of Psychology, University of Southampton, Highfield, Southampton, SO17 1BJ, UK \\ (Correspondence should be addressed to T C Skinner; Email: T.C.Skinner@soton.ac.uk)
}

\begin{abstract}
Type 2 diabetes treatment outcomes ultimately depend on patients and their ability to make longterm behavioural changes that support good self-care and metabolic control. Patients' perceptions about diabetes and diabetes-related complications can have a strong influence on their emotional well-being, as well as day-to-day self-care and the quality of metabolic control. The gravity of diabetes is often underestimated, and many patients do not understand the link between poor glycaemic control and long-term complications of the disease. Similarly, people with diabetes commonly undervalue the role of lifestyle changes and pharmacological therapy in preventing future complications. Negative emotions and preconceptions about treatment can also discourage adherence to treatment plans. 'Psychological insulin resistance' caused by fear and concerns about insulin and daily insulin injections can discourage many patients from starting insulin therapy, even if oral agents have failed. Depression, stress and anxiety represent further obstacles to optimum self-care and the attainment of glucose goals.

Healthcare professionals should endeavour to understand and accommodate these issues when setting personal treatment goals and developing plans to achieve them. Importantly, the advice and support they provide should be tailored to the unique needs of each patient. There is scope to improve outpatient consultations to ensure agreement between patients and professionals concerning issues discussed and decisions made, and this may help to improve recall and motivation to manage diabetes. Engaging patients in the goal-setting process can help to overcome potential barriers to good self-care and may increase the probability that treatment goals are achieved.
\end{abstract}

European Journal of Endocrinology 151 T13-T17

\section{Who sets the goals?}

Clinical trials have unequivocally demonstrated that good glycaemic control improves clinical or physiological outcomes $(1,2)$. However, a similar abundance of studies continue to document that sub-optimal control of blood glucose, blood pressure and lipids remains common in the vast majority of clinical populations $(1,2)$. One of the challenges to changing this problem is the fact that nearly all the day-to-day, minute-byminute decisions which affect patient outcomes (e.g. diet, physical activity, taking medication, blood glucose monitoring etc) are made by the individual with diabetes. As such, the individual is responsible for managing their condition (except when they have a mental disability that prevents them from making informed decisions). Furthermore, nearly all the barriers to the effective self-management of diabetes lie in individuals' personal and social worlds. This means that healthcare professionals need to do more than provide information to people with diabetes. They also need to support them in the development of general self-management skills necessary for the effective management of a chronic condition (e.g. goal setting, action planning and problem solving), and diabetes-specific self-management skills necessary for the effective management of type 2 diabetes (e.g. self-monitoring, management of hypo- and hyperglycaemia, foot care, cardiovascular risk etc).

Patients make what they believe to be the best decisions to achieve the best possible quality of life, as they perceive it. As a result, patients' perceptions of diabetes and their attitudes to therapy may profoundly affect their treatment outcomes. Joint decisions about what is the right treatment for an individual may take away many of the difficulties experienced in adhering to an inappropriate or cumbersome regimen. Acknowledgement of this has substantial implications for the delivery of healthcare, as it means that prescribing the right treatment regimen for the right person is only a small part of diabetes care.

\section{Efficacy of diabetes consultations}

If all the day-to-day, minute-to-minute decisions that affect diabetes outcomes are made by the individual with diabetes, we need to reflect on how our practice reflects this important fact. There is a danger that patients will stop listening if they are barraged with a fixed list of do's and don'ts about diabetes care and if they are told what they need to do. Studies indicate that healthcare professionals may need to reassess the way they conduct consultations with their diabetes 
patients in order to improve their concordance with patients over the main issues to be discussed and to enhance recall of the issues discussed and decisions made. When patients and professionals were asked independently to recall a consultation, one in five participants completely disagreed about both the issues discussed and the decisions made in the consultation; there was some agreement (at least one topic listed by both parties) for $52 \%$ of consultations, and complete agreement (same topics listed in same detail by both parties) for only $28 \%$ of consultations (3). This finding does not seem to be accounted for by patients forgetting what was discussed - a substantial proportion of patients and professionals reported completely different topics of discussion and there was only $45 \%$ congruency for decisions made. Furthermore, in a separate study, when consultations were videoed to provide a permanent record of what actually happened, approximately one-third of the issues discussed in most consultations could not be recalled by the patient or professional ((4); Fig. 1).

One of the reasons why patients have poor recall of consultations could be that the clinical and biochemical parameters discussed, for example glycated haemoglobin $\left(\mathrm{HbA}_{1 \mathrm{c}}\right)$ levels, blood pressure and cholesterol levels, are not discussed in a way that is meaningful to them. Many patients do not know what these measurements are, why they are measured, or what the targets for measures mean. Therefore, communicating these goals to patients in a way that is relevant to them should help to increase their motivation and confidence to take control of their diabetes. Simple tools can be used to assist in this process; in some UK diabetes self-management education programmes, for example, patients are asked to plot their metabolic profile (blood pressure, cholesterol, blood sugars, smoking status, body shape) and depression rating on a chart that is colour-coded to give them an indication of their risk for complications associated with each measurement (Fig. 2). Engaging people with such simple tools and asking them how they want to respond to their risks or which risk factor they want to work on

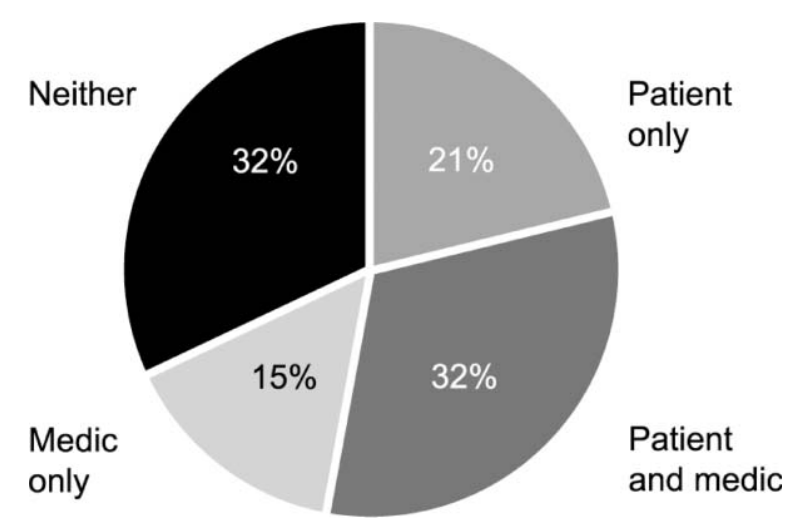

Figure 1 Patient and professional recall of a consultation (4). first may assist the joint goal-setting process and enhance motivation for self-care.

Deciding which risk factors to work on is only the first step of the process of engaging people in the selfmanagement of their condition. There is generally more than one way to improve a particular clinical parameter (e.g. taking medication, physical activity and different aspects of food choices) and it may be beneficial to engage patients in discussing these options so that they can help decide what they would like to do in order to reach their treatment goal. For example, blood pressure can be reduced by any one of a long list of interventions including eating less, eating more fruit and vegetables, reducing fat intake, moderating alcohol consumption, giving up smoking, increasing physical activity, taking medication appropriately and reducing salt intake. Involving patients in a selective goal-setting process can increase the likelihood that realistic plans are made to achieve their goals, thereby increasing the probability of success.

The behavioural changes needed to achieve good metabolic control may be very specific to the patient, and treatment plans should be tailored accordingly. For example, a 40-year-old female with type 2 diabetes, who attended a diabetes education session in the UK, decided that she wanted to reduce her blood pressure. It was agreed that she would do this by reducing her salt intake; this was achieved by her storing salt in the fridge so that she would pause and think before adding salt to her food. Without such a tailored approach it may be difficult to predict exactly what combination of treatment and behaviour changes will be the most effective for any one patient.

\section{Patients' perceptions about diabetes}

Perceptions about diabetes, diabetes-related complications and its treatment can have a major influence on self-care, emotional well-being and glycaemic control. Many patients do not fully comprehend the seriousness of diabetes, which will undoubtedly affect their dedication to day-to-day self-care. Studies have shown that only $64 \%$ of patients newly diagnosed with diabetes believe that diabetes is a life-long condition $(6,7)$. Similarly, only $76 \%$ of patients with long-standing diabetes, and $86 \%$ of adolescent patients with type 1 diabetes, agree that diabetes is a chronic disease. Approximately $22 \%$ of patients believe that diabetes will not have much effect on their health and only $9 \%$ are aware that their life will be shorter because of it $(8-10)$. Patients with diabetes generally underestimate the value of lifestyle changes and medication in preventing diabetes complications, and many rate 'getting regular medical tests to see if you have them' as the most important preventative strategy, rather than the active self-care behaviour healthcare professionals are trying to encourage. 
NAME

D.O.B

GP'S NAME

\begin{tabular}{|l|l|r|r|r|r|r|r|r|r|r|r|r|}
\hline BLOOD PRESSURE & $\begin{array}{l}\text { Less } \\
\text { than } 130\end{array}$ & 135 & 140 & 145 & 150 & 155 & 160 & 165 & 170 & 175 & 180 & $\begin{array}{l}\text { More } \\
\text { than } 85\end{array}$ \\
\hline BP SYSTOLIC DIASTOLIC & $\begin{array}{l}\text { Less } \\
\text { than } 70\end{array}$ & 75 & 80 & 85 & 90 & 95 & 100 & 105 & 110 & 115 & 120 & $\begin{array}{l}\text { More } \\
\text { than } 125\end{array}$ \\
\hline
\end{tabular}

\begin{tabular}{|c|c|c|c|c|c|c|c|c|c|c|c|c|}
\hline \multicolumn{13}{|l|}{ BLOOD FATS } \\
\hline CHOLESTEROL & $\begin{array}{l}\text { Less } \\
\text { than } 2.1\end{array}$ & 3.0 & 3.1 & 4 & 4.1 & 5 & 5.1 & 6 & 6.1 & 7 & 7.1 & $\begin{array}{r}\text { More } \\
\text { than } 8.0\end{array}$ \\
\hline HDL & $\begin{array}{l}\text { More } \\
\text { than } 1.5\end{array}$ & 1.4 & & 1.2 & 1.1 & 1.0 & & 0.8 & 0.7 & 0.6 & 0.5 & $\begin{array}{r}\text { Less } \\
\text { than } 4.0\end{array}$ \\
\hline
\end{tabular}

\begin{tabular}{|c|c|c|c|c|c|c|c|c|c|c|c|c|}
\hline \multicolumn{13}{|l|}{ BLOOD SUGARS } \\
\hline BLOOD GLUCOSE & $\begin{array}{l}\text { Less } \\
\text { than } 5\end{array}$ & 6 & 7 & 8 & 9 & 10 & 11 & 12 & 13 & 14 & 15 & $\begin{array}{r}\text { More } \\
\text { than } 16\end{array}$ \\
\hline $\mathbf{H B A}_{1 \mathrm{C}}$ & $\begin{array}{l}\text { Less } \\
\text { than } 6.5\end{array}$ & 6.9 & 7.0 & 7.5 & 7.6 & 8.0 & 8.1 & 8.5 & 8.6 & 9.0 & 9.1 & $\begin{array}{r}\text { Less } \\
\text { than } 9.5\end{array}$ \\
\hline
\end{tabular}

\begin{tabular}{|c|c|c|}
\hline SMOKING & PASSIVE & SMOKER \\
\hline
\end{tabular}

\begin{tabular}{|l|l|lll|lll|l|}
\hline SHAPE & Less than $69 \mathrm{cms}$ & 70 & cms & 94 & 95 & cms & 102 & $\begin{array}{l}\text { More than } 103 \mathrm{cms} \\
\text { inches }\end{array}$ \\
\hline MALE & Less than 27 inches & 28 & inches & 37 & 38 & More than 41 inches \\
\hline FEMALE & Less than $60 \mathrm{cms}$ & 61 & cms & 80 & 81 & cms & 88 & More than $89 \mathrm{cms}$ \\
& Less than 23.5 inches & 24 & inches & 31.5 & 32 & inches & 34.5 & More than 35 inches \\
\hline
\end{tabular}

\begin{tabular}{|c|c|c|c|c|c|c|c|c|c|c|c|c|c|}
\hline \multicolumn{14}{|c|}{ DEPRESSION } \\
\hline 0 & 3 & 4 & 6 & 7 & 9 & 10 & 12 & 13 & 15 & 16 & 18 & 19 & 21 \\
\hline
\end{tabular}

Figure 2 Diabetes health profile. (From (5), reprinted with permission from the American Diabetes Association). 
Perceptions about the efficacy of treatment, and negative emotions such as anger and fear, may also affect self-care. Misconceptions and negative attitudes to insulin therapy are frequently reported by both patients and healthcare professionals $(11-16)$. Negative attitudes to insulin include: concerns about dependency and loss of personal freedom; fear of injections, hypoglycaemia and weight gain; worries about the general inconvenience of injections and proper injection techniques; and beliefs that the need to start insulin therapy reflects a worsening of diabetes and failure to manage the disease.

Diabetes patients throughout the world have similar fears and concerns about insulin. Indeed, many patients are reluctant to start insulin therapy despite poor glycaemic control with oral agents, a phenomenon known as 'psychological insulin resistance'. These attitudes may be based on personal experience, observation, hearsay and interactions with healthcare professionals (15). A study by Lauritzen et al. (17) suggests that negative attitudes to insulin may, in many cases, begin with the physician. We should choose the words we use to speak to our patients very carefully or we may inadvertently decrease their willingness to accept a therapy that is most likely to become essential (17).

\section{Depression in diabetes}

Reviews and meta-analyses indicate that depression is at least twice as prevalent in people with diabetes compared with the general population (18) and, even after successful treatment, can recur in up to $80 \%$ of cases (19). Among patients with diabetes, depression is often associated with poor glycaemic control and the presence of micro- and macrovascular complications (20-22). Although antidepressant therapy may improve mood and, in some cases, improve glycaemic control (23), depression is both underdiagnosed and undertreated in patients with diabetes. Further studies are required to establish a link between antidepressant therapy and improved glycaemic control.

The Diabetes Attitudes, Wishes and Needs (DAWN) study, a psychosocial diabetes study involving more than 5000 people with diabetes and 3000 healthcare professionals, showed that emotional well-being is pivotal to achieve effective self-management (24). However, as shown in Fig. 3, people with diabetes frequently reported feelings of poor well-being, stress and anxiety. Thus, combining psychosocial support with medical care may markedly improve diabetes outcomes.

\section{Goal-setting and treatment outcomes}

It is possible to integrate the principles of effective selfmanagement education with clinical care of diabetes, which results in changes in patient outcomes. Both Trento and colleagues in Italy (25) and Rachmani and colleagues in Israel, provide exemplary models of this in the published literature (26). However, to achieve improved outcomes, healthcare professionals need to create an understanding of the reality of diabetes for their patient by:

- Providing patients with honest, up-to-date, evidence-based information regarding the causes, effects and options for the management of type 2 diabetes.

- Supporting patients in understanding their own beliefs and the information provided to them.

- Supporting patients in the development of general self-management skills, e.g. goal-setting.

- Supporting patients in the development of general diabetes-specific self-management, e.g. blood glucose/urine monitoring.

- Enabling patients to discuss methods of reducing their identified risk factors, supporting them in developing their own diabetes management plan and providing the opportunity for them to reflect on their day-to-day self-management.

Diabetes cannot be managed successfully by doctors alone, and treatment outcomes will ultimately depend on the active participation of patients in their care. If we want to change diabetes outcomes, we need to change the goal-setting process so that patients are informed, involved and supported in their self-care. Engaging patients in the goal-setting process will
'I am tired of complying with my medication'

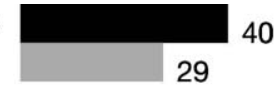

'I feel burned out from having to cope with diabetes'

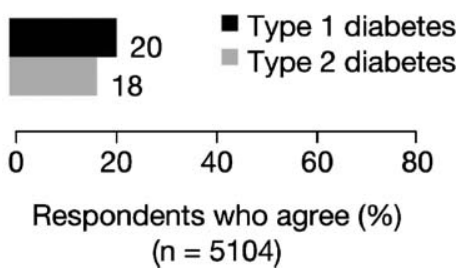

$(n=5104)$

Figure 3 Patient's self-report of diabetes-related distress. Results from the DAWN (Diabetes Attitudes, Wishes and Needs) study conducted by Novo Nordisk in collaboration with the IDF ((23), reprinted with permission from Novo Nordisk). 
enhance diabetes care, increase the probability that goals are achieved and improve diabetes outcomes.

\section{References}

1 Diabetes Control and Complications Research Group, Diabetes Control and Complications trial (DCCT): Update. Diabetes Care $199413427-433$.

2 UK Prospective Diabetes Study Group, Intensive blood-glucose control with sulphonylureas or insulin compared with conventional treatment and risk of complications in patients with type 2 diabetes (UKPDS 33). The Lancet 1998352 837-853.

3 Parkin T \& Skinner TC. Discrepancies between patient and professionals recall and perception of an outpatient consultation. Diabetic Medicine 200320 909-914.

4 Skinner TC, Mehrshahi R, Gregorry R \& Jackson S. Who remembers what happened in the consultation? Comparing patient and doctor recall with the video evidence. Diabetologia 200346 (Suppl 2) 246 .

5 Skinner C, Cradock S, Arundel F \& Graham W. Four theories and a philosophy: self-management education for individuals newly diagnosed with type 2 diabetes. Diabetes Spectrum $2003 \mathbf{1 6}$ $75-80$.

6 Arundel F, Cradock S, Noeken J \& Skinner TC. Phase 1 evaluation of Starting Out With Type 2 Diabetes: A self-management education workshop for the newly diagnosed. Diabetic Medicine 200320 (Suppl 2) 76.

7 Tringham J, Skinner TC, Arundel F, Cradock S, Noeken J, Khunit K, Jarivs J, Farooqui A \& Davies MJ. Health beliefs of those with screen detected diabetes are different to those diagnosed conventionally. Diabetic Medicine 200320 (Suppl 2) 79.

8 Skinner TC, John M \& Hampson SE. Social support and personal models of diabetes as predictors of self-care and well-being: a longitudinal study of adolescents with diabetes. Journal of Pediatric Psychology 200025 257-267.

9 Skinner TC, Tantam L, Purchon A \& John M. Do illness beliefs explain poorer outcomes for ethnic minority populations: a pilot study. Diabetic Medicine 200219 (Suppl 2) P274.

10 Skinner TC, Tringham J, Khunit K, Jarivs J, Farooqui A \& Raymond N. Illness beliefs of individuals participating in the STAR Diabetes Screening study. Diabetic Medicine 200320 (Suppl 2) 24.

11 Bashoff EC \& Beaser RS. Insulin therapy and the reluctant patient. Overcoming obstacles to success. Postgraduate Medicine 199597 $86-90,93-96$.

12 Weedon L \& Curry M. Diabetes. Switching to insulin. Nursing Times $19928834-36$.
13 Wolffenbuttel BH, Drossaert $\mathrm{CH}$ \& Visser AP. Determinants of injecting insulin in elderly patients with type II diabetes mellitus. Patient Education and Counselling 199322 117-125.

14 Miller F. When the client says 'no way' to insulin therapy. Diabetes Education 199521187.

15 Hunt LM, Valenzuela MA \& Pugh JA. NIDDM patients' fears and hopes about insulin therapy. The basis of patient reluctance. Diabetes Care 199720 292-298.

16 Mull DS, Nguyen N \& Mull JD. Vietnamese diabetic patients and their physicians: what ethnography can teach us. The Western Journal of Medicine 2001175 307-311.

17 Lauritzen T \& Scott A. Barriers to insulin therapy in type 2 diabetes: a qualitative focus group research among patients, GPs and diabeteologists. European Union of General Practitioners Clinical Journal 2001 36-44.

18 Anderson RJ, Freedland KE, Clouse RE \& Lustman PJ. The prevalence of comorbid depression in adults with diabetes: a meta-analysis. Diabetes Care 200124 1069-1078.

19 Lustman PJ, Griffith LS \& Clouse RE. Depression in Adults with Diabetes. Seminars in Clinical Neuropsychiatry 19972 15-23.

20 Lustman PJ, Griffith LS, Freedland KE \& Clouse RE. The course of major depression in diabetes. General Hospital Psychiatry 199719 138-143.

21 Lustman PJ, Anderson RJ, Freedland KE, de Groot M, Carney RM \& Clouse RE. Depression and poor glycemic control: a meta-analytic review of the literature. Diabetes Care 200023 934-942.

22 de Groot M, Anderson R, Freedland KE, Clouse RE \& Lustman PJ. Association of depression and diabetes complications: a meta-analysis. Psychosomatic Medicine 200163 619-630.

23 Lustman PJ, Clouse RE \& Freedland KE. Management of major depression in adults with diabetes: implications of recent clinical trials. Seminars in Clinical Neuropsychiatry $19983102-114$.

24 The DAWN (Diabetes Attitudes, Wishes and Needs) Study. Practical Diabetes International $20021922-24$.

25 Trento M, Passera P, Bajardi M, Tomalino M, Grassi G, Borgo E, Donnola C, Cavallo F, Bondonio P \& Porta M. Lifestyle intervention by group care prevents deterioration of type II diabetes: a 4-year randomized controlled clinical trial. Diabetologia 2002 $451231-1239$.

26 Rachmani R, Levi Z, Slavachevski I, Avin M \& Ravid M. Teaching patients to monitor their risk factors retards the progression of vascular complications in high-risk patients with type 2 diabetes mellitus - a randomized prospective study. Diabetic Medicine 2002 $19385-392$.

Received 19 May 2004

Accepted 24 May 2004 